\section{Apoptotic mesenchymal stromal cells induce prostaglandin E2 in monocytes: implications for the monitoring of mesenchymal stromal cell activity}

Extensive experience with mesenchymal stromal cells (MSC) in the treatment of inflammatory disorders has provided convincing evidence to support their clinical efficacy in selected cases, especially in steroid-resistant acute graft-versus-host disease (GvHD). ${ }^{1,2}$ Although MSC can induce immunosuppression directly through the secretion of soluble factors and contact-mediated mechanisms, it is becoming clearer that the recruitment of recipient immunoregulatory networks is fundamental for delivering the therapeutic effects of these cells. ${ }^{3} \mathrm{We}$ recently identified a novel mechanistic pathway by which MSC mediate immunosuppression in GvHD. Following contact with recipient cytotoxic cells, MSC undergo in vivo apoptosis and are efferocytosed by phagocytes which are then induced to upregulate indoleamine 2,3-dioxygenase (IDO). Therefore, to accomplish MSC immunosuppression, patients must have activated cytotoxic cells and competent phagocytes. While the magnitude of MSC apoptosis induced by recipient cytotoxic cells can provide a biomarker predictive of clinical responses to MSC, ${ }^{4}$ there are no tools to monitor the immunological effects of MSC following efferocytosis. In order to identify potential molecules for monitoring MSC immunological effects in patients, we investigated the molecular and functional profile of human monocytes exposed to apoptotic MSC (ApoMSC).

We isolated $\mathrm{CD}_{14}{ }^{+}$monocytes from the peripheral blood of healthy donors (Online Supplementary Methods) because of their recognized role in engulfing dead MSC. MSC were isolated and expanded as previously described, ${ }^{4}$ and induced to undergo apoptosis using antiFas monoclonal antibody (CH11, Merck). ApoMSC were characterized by annexin-V (BD Biosciences) staining and immunoblotting for activated caspase-3 (Cell Signaling) (Online Supplementary Methods and Online Supplementary Figure $S 1 A-C$ ). CellTrace ${ }^{\mathrm{TM}}$ Violet (Thermo Fisher Scientific)-labeled (staining concentration: $1 \mu \mathrm{M}$ ) monocytes were cultured with ApoMSC labeled with 20 $\mathrm{ng} / \mathrm{mL} \mathrm{pH}$-sensitive fluorescent dye $\mathrm{pHrodo}^{\mathrm{TM}} \mathrm{Red}^{6}$ (Thermo Fisher Scientific). Efferocytosis was determined by quantitating $\mathrm{pHrodo}^{\mathrm{TM}}$ Red fluorescence (mean fluorescence intensity, MFI) in monocytes using flow cytometry or CSU-X1 Spinning-Disk Confocal. Confocal data were processed with NIS Elements AR (Nikon) software. After $2 \mathrm{~h}$, monocytes rapidly engulfed ApoMSC but not the non-apoptotic MSC (Online Supplementary Figure S2A$B)$. ApoMSC efferocytosis was enhanced in the presence of lipopolysaccharide (LPS, $100 \mathrm{ng} / \mathrm{mL}$, Sigma-Aldrich) to model inflammation ${ }^{7}$ (Figure 1A). When exposure to ApoMSC was extended to $24 \mathrm{~h}$, the magnitude of efferocytosis was increased (Figure 1B,C).

Apoptotic cell clearance is generally regarded as immune-silencing, although under particular circumstances, it can elicit immune responses. ${ }^{8}$ To examine the immunomodulatory activity of ApoMSC-conditioned monocytes (ApoMSC-Mono), we measured their ability to inhibit CD3/CD28-induced T-cell proliferation. CD3 T cells were isolated from the peripheral blood of healthy donors (Online Supplementary Methods). Monocytes were cultured with ApoMSC for $8 \mathrm{~h}$, and then added to

Table 1. Patients' characteristics.

\begin{tabular}{|c|c|c|c|c|c|c|c|c|}
\hline Diagnosis & $\begin{array}{l}\text { Age \& } \\
\text { gender }\end{array}$ & $\begin{array}{l}\text { Donor } \\
\text { types }\end{array}$ & $\begin{array}{l}\text { GrHD } \\
\text { grade }\end{array}$ & $\begin{array}{l}\text { GvHD } \\
\text { organs }\end{array}$ & $\begin{array}{l}\text { Pre-MSC } \\
\text { therapy }\end{array}$ & $\begin{array}{l}\text { Conditioning } \\
\text { regimen }\end{array}$ & $\begin{array}{c}\text { MSC } \\
\left(x 10^{6} / \mathrm{Kg}\right)\end{array}$ & Response \\
\hline B-ALL & $47, \mathrm{M}$ & MSD, PBSCT & III & Liver, Skin & $\begin{array}{l}\text { Steroids, } \\
\text { ECP, CsA }\end{array}$ & $\begin{array}{c}\text { Etoposide phosphate; } \\
\text { TBI }\end{array}$ & 2.01 & NR \\
\hline
\end{tabular}

\begin{tabular}{|c|c|c|c|c|c|c|c|c|}
\hline PMF & $63, \mathrm{M}$ & MUD, PBSCT & III & Gut & CsA, Prednisolone & $\begin{array}{c}\text { Busulfan } \\
\text { Fludarabine }\end{array}$ & 1.02 & NR \\
\hline sAML & $58, \mathrm{M}$ & MUD, PBSCT & IV & Gut & CsA, Prednisolone & Busilvex Fludarabine & 1.02 & NR \\
\hline MDS-EB2 & $67, \mathrm{M}$ & PBSCT & IV & Liver, Gut & Steroids, Ruxolitinib & $\begin{array}{c}\text { Fludarabine; } \\
\text { Busulfan }\end{array}$ & 2.28 & NR \\
\hline ALK-ALCL & $45, \mathrm{M}$ & MSD, PBSCT & IV & Skin, Gut & $\begin{array}{c}\text { Prednisolone, } \\
\text { Ruxolitinib, MSC, MMF }\end{array}$ & $\begin{array}{c}\text { Busilvex; } \\
\text { Cyclophosphamide; } \\
\text { Fludarabine }\end{array}$ & $\begin{array}{c}2.23^{\dagger} \\
\& \\
2.18^{\ddagger}\end{array}$ & PR \\
\hline rAML & $62, \mathrm{~F}$ & MRD, PBSCT & IV & Liver, Gut & CsA, Prednisolone & $\begin{array}{c}\text { Busilvex; } \\
\text { Fludarabine }\end{array}$ & 2.28 & PR \\
\hline MM & $68, \mathrm{M}$ & MUD, PBSCT & IV & Gut & CsA, Prednisolone & $\begin{array}{l}\text { Rhenium-anti-CD66; } \\
\text { Fludarabine; Treosulfan }\end{array}$ & 1.05 & PR \\
\hline AML & $58, \mathrm{M}$ & PBSCT & IV & $\begin{array}{l}\text { Skin, } \\
\text { Liver, } \\
\text { Gut }\end{array}$ & $\begin{array}{c}\text { CsA, } \\
\text { PPrednisolon } \\
\text { ECP, } \\
\text { Ruxolitinib }\end{array}$ & $\begin{array}{c}\text { Fludarabine; } \\
\text { Busulfan }\end{array}$ & 1.05 & PR \\
\hline
\end{tabular}

:First dose. : Second dose. GvHD: graft-versus-host disease; MSC: mesenchymal stromal cells; B-ALL: B-cell acute lymphoblastic leukemia; PMF: primary myelofibrosis; sAML: secondary AML; MDS-EB2: myelodysplastic syndrome with excess blasts type 2; ALK-ALCL: anaplastic lymphoma kinase-negative anaplastic large cell lymphoma; rAML: relapsed AML; MM: multiple myeloma;AML: acute myeloid leukemia; M: male; F: female; MUD: HLA-matched unrelated donor; PBSCT: peripheral blood stem cell transplant; MSD: HLA-matched sibling donor; MRD: HLA-matched related donor; ECP: extracorporeal photopheresis; CsA: cyclosporine; MMF: mycophenolate mofetil; TBI: total body irradiation; NR: non-responder; R: responder. 
CellTrace ${ }^{\mathrm{TM}}$ Violet-labeled T cells $\left(10^{3}\right.$ cells $\left./ \mu \mathrm{L}\right)$ stimulated with CD3/CD28 (Thermo Fisher Scientific) at a 1:1 cellto-bead ratio for 3 days. The proportion of proliferating $T$ cells was quantitated using flow cytometry. Remarkably, the ApoMSC-Mono inhibited $50 \%$ of the T-cell proliferation relative to the monocytes or ApoMSC alone (Figure 1D). Indeed, ApoMSC alone did not exhibit any inhibitory effect, suggesting that monocytes are required to inhibit $\mathrm{T}$-cell proliferation. Besides, it also excludes the possibility that there are any remaining non- apoptotic MSC producing immunosuppressive effects.

We then characterized the molecular profile of ApoMSC-Mono by evaluating the expression of selected molecules known to effect immunosuppression. CellTrace $^{\mathrm{TM}}$ Violet-labeled monocytes were cultured with ApoMSC. After $8 \mathrm{~h}$, the monocytes were stained with anti-human IDO-PE (eyedio), cyclooxygenase2 (COX2)PE (AS67) and programmed death-ligand 1 (PD-L1)-PECy7 (29E.2A3) antibody and analyzed using flow cytometry. Notably, IDO, COX2 and PD-L1 were significantly
A

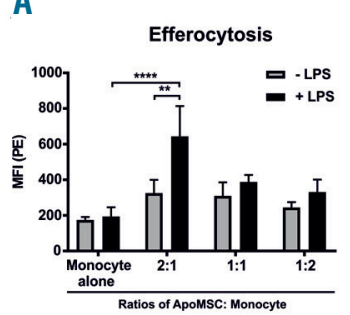

D

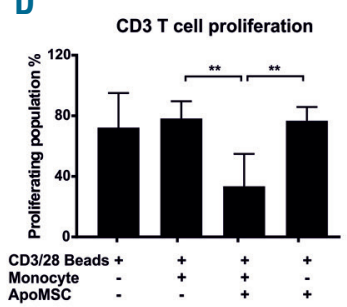

H

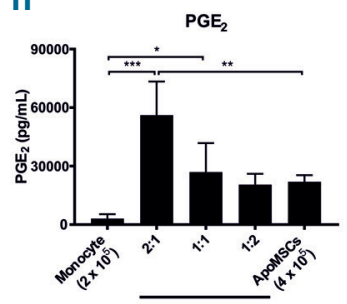

Ratios of ApoMSC: Monocyte

L

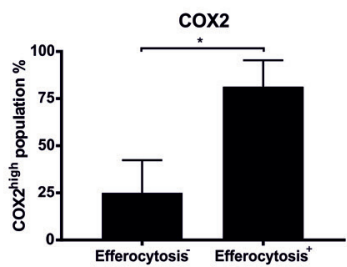

B

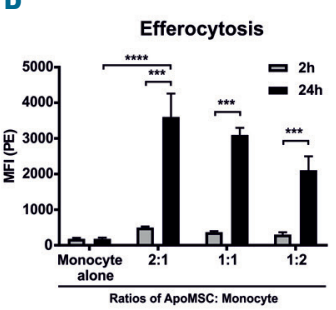

E

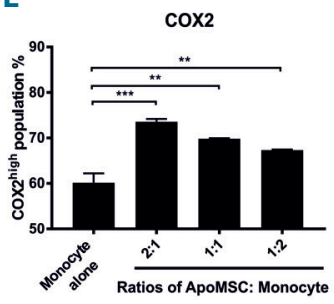

I

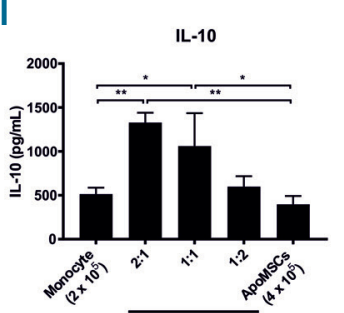

Ratios of ApoMSC: Monocyte

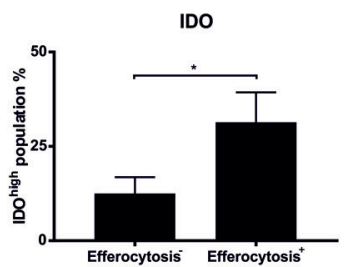

C

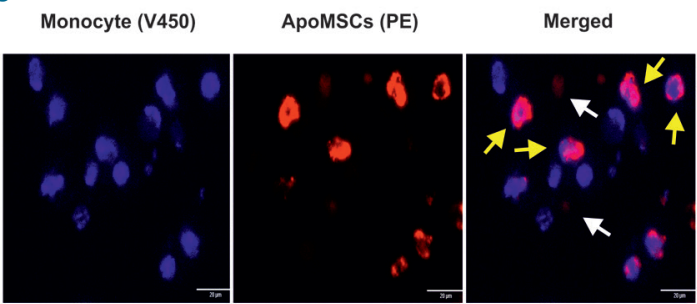

F

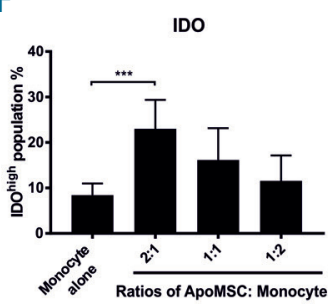

G

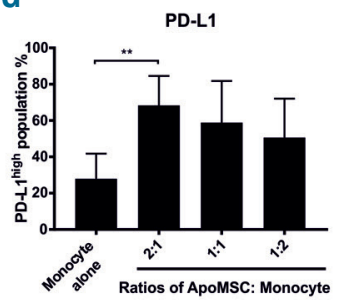

J

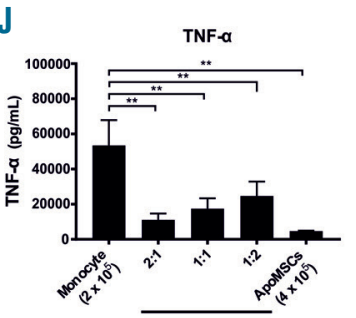

Ratios of ApoMSC: Monocyte

K

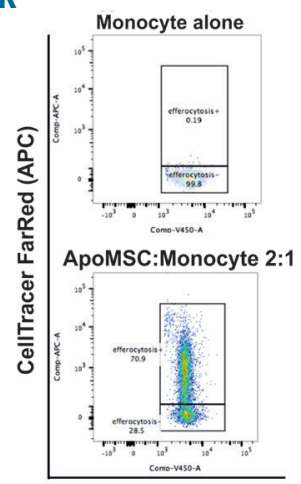

CellTracer Violet (V450)

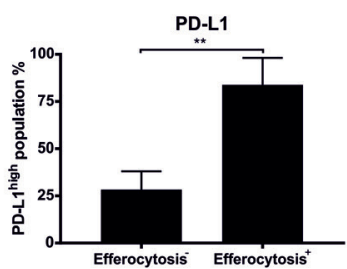

Figure 1. Efferocytosis of apoptotic mesenchymal stromal cells polarizes monocytes into an immunosuppressive phenotype. (A) Apoptotic mesenchymal stromal cells (ApoMSC) were stained with $20 \mathrm{ng} / \mathrm{mL}^{\mathrm{pH}} \mathrm{Hrodo}^{\mathrm{TM}}$ Red-succinimidyl ester (PE) while isolated monocytes were stained with $1 \mu \mathrm{M}$ CellTrace ${ }^{\mathrm{TM}}$ Violet (V450). Monocytes were cultured with different amounts of ApoMSC for $2 \mathrm{~h}$ at $37^{\circ} \mathrm{C}, 5 \% \mathrm{CO}_{2}$. Lipopolysaccharide (LPS) $100 \mathrm{ng} / \mathrm{mL}$ was used to stimulate monocytes. The mean fluorescence intensity (MFI) (PE) within the monocyte population was measured as an indicator of efferocytosis, $\mathrm{n}=3$. (B) MFI (PE) after 2 and $24 \mathrm{~h}$ was compared among the different groups, $\mathrm{n}=3$. (C) Confocal images of monocytes efferocytosing ApoMSC after $24 \mathrm{~h}$ in culture. The yellow arrows indicate the monocytes engulfing ApoMSC while the white arrows indicate ApoMSC alone. The bar represents 20 um. (D) Monocytes ( $2 \times 10^{5} /$ well) were co-cultured with ApoMSC $\left(4 \times 10^{5} /\right.$ well) for $8 \mathrm{~h}$. CellTrace ${ }^{\mathrm{TM}}$ Violet-labeled CD3 T cells $\left(2 \times 10^{5} /\right.$ well) were added to the cultures and stimulated by CD3/CD28 beads at a $1: 1$ cell:bead ratio for 3 days. The percentages of proliferating $T$ cells were measured by flow cytometry according to the loss of fluorescence intensity due to cell division, $n=4$. (E-G) Intracellular and surface staining was performed to examine the expression of different proteins, including COX2, IDO and PD-L1, in monocytes. The $\operatorname{COX} 2^{\text {high }}, n=3(E), I D 0^{\text {high }}, n=4(F)$ and $P D-L 1^{\text {high }}, n=3(G)$ populations were gated according to the monocyte alone control (used as a negative control). $(\mathrm{H}-\mathrm{J})$ Enzyme-linked immunosorbent assays were performed to assess the amount of PGE2, $n=4(\mathrm{H}), \mathrm{IL}-10, \mathrm{n}=3$ (I) and TNF- $\alpha, n=6(\mathrm{~J})$ in cell culture supernatants. (K) To select the monocytes according to efferocytosis, ApoMSC were fluorescent-labeled with CellTrace ${ }^{\mathrm{TM}}$ FarRed $\left(\mathrm{APC}^{+}\right)$while monocytes were labeled with CellTrace ${ }^{\mathrm{TM}}$ Violet $\left(\mathrm{V}^{4} 50^{+}\right)$. $\mathrm{APC}^{+}$monocytes were regarded as efferocytosis ${ }^{+}$and $\mathrm{APC}^{-}$monocytes were regarded as efferocytosis ${ }^{-}$. (L) Bar charts showing the difference of $\mathrm{COX}^{\text {high }}, \mathrm{IDO}^{\text {high }}$ and PD-L1 ${ }^{\text {high }}$ populations between the efferocytosis ${ }^{+}$and efferocytosis- monocytes, $\mathrm{n}=3$. Experimental data are expressed as means \pm standard deviation. An unpaired $t$ test was used to compare the mean differences between two samples. One-way analysis of variance and the posthoc Tukey test were used to compare the mean differences among the samples $(* P<0.05 ; * * P<0.01 ; * * * P<0.001 ; * * * * P<0.0001)$. 
upregulated in ApoMSC-Mono (Figure 1E-G). Enzymelinked immunosorbent assays (all from Thermo Fisher Scientific) were used to examine the secreted soluble factors in culture supernatants. We found that the secretion of PGE2 and interleukin-10 (IL-10) was markedly increased, but tumor necrosis factor- $\alpha$ (TNF- $\alpha$ ) was reduced compared to that of monocytes or ApoMSC alone (Figure $\mathrm{H}-\mathrm{J}$ ). Overall the data suggest that monocytes exhibited a functional and molecular immunosuppressive phenotype following efferocytosis of ApoMSC. To confirm the association between efferocytosis and the production of these immunosuppressive molecules, ApoMSC were labeled with CellTrace ${ }^{\mathrm{TM}}$ FarRed (APC, Thermo Fisher Scientific) (Figure 1K). The increased expression of COX2, IDO and PD-L1 was detected selec- tively in the monocytes engulfing ApoMSC (APC ${ }^{+}$

(Figure 1K-L).

Intriguingly, previous studies have indicated that PGE2 can induce IDO, PD-L1 and IL-10. ${ }^{9-11} \mathrm{We}$, therefore, investigated the dependence of these molecules on COX2/PGE2 activity. During the monocyte-conditioning, a selective COX2 inhibitor NS-398 (100 $\mu \mathrm{M}$, Cayman) was added to inactivate COX2 in monocytes. The COX2 inhibition of monocytes was sufficient to prevent the induction of IDO, PD-L1 and IL-10, without interfering with efferocytosis (Figure 2A-E). Importantly, it significantly impaired the immunosuppressive activity of ApoMSC-Mono on in vitro T-cell proliferation (Figure $2 \mathrm{~F}$ ). Collectively, these findings reveal the ultimate role of efferocytosis-induced COX2/PGE2 in delivering
A

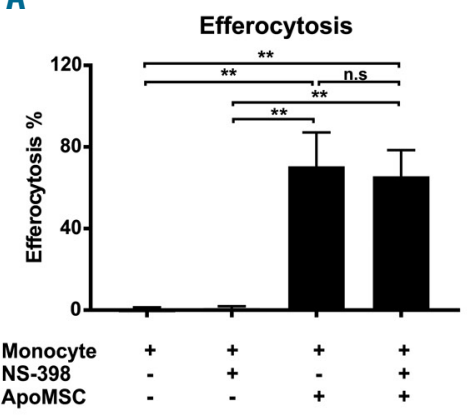

C

IL-10

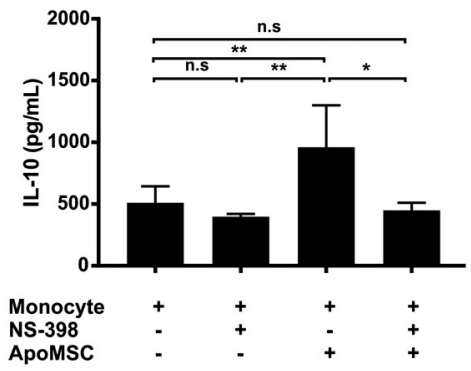

$\mathrm{F}$

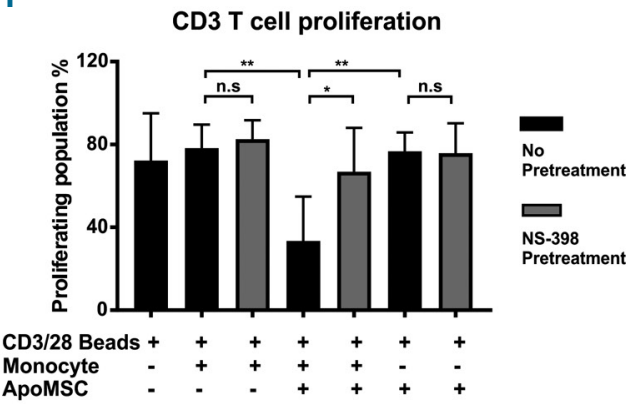

B

D
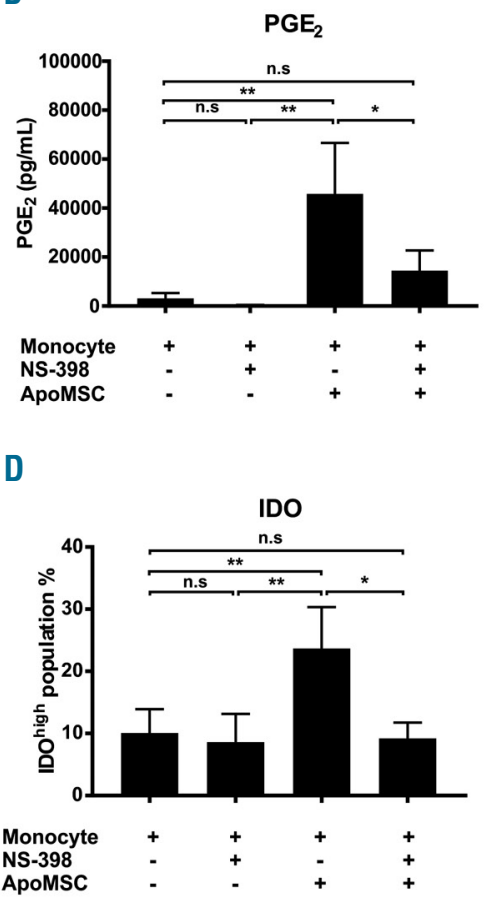

E

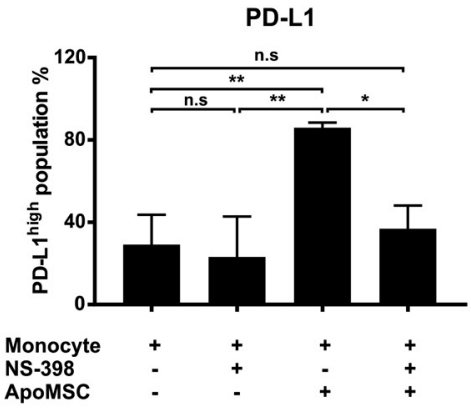

G
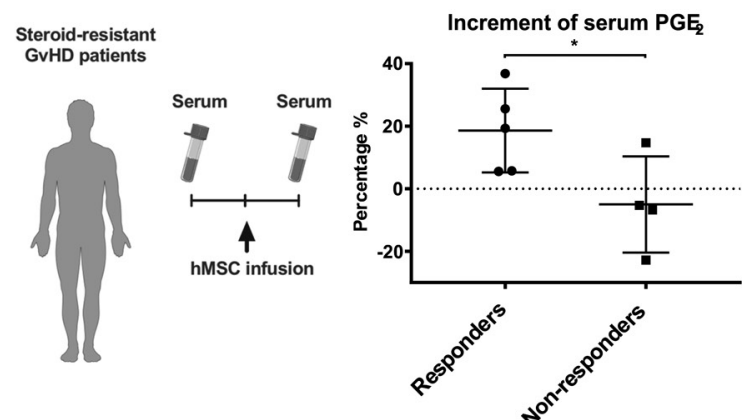

Figure 2. Efferocytosis-induced COX2/PGE2 is the key effector molecule of immunosuppressive monocytes. (A) NS-398 (100 $\mu \mathrm{M})$ was added during the coculture of monocytes and apoptotic mesenchymal stromal cells (ApoMSC). After $8 \mathrm{~h}$, efferocytosis was evaluated using flow cytometry, $\mathrm{n}=3$. As reported in (A), PGE2, $n=4(B)$ and IL-10, $n=4$ (C) were evaluated in cell culture supernatants using enzyme-linked immunosorbent assays, while IDO, $n=5$ (D) and PD-L1, $n=3$ $(E)$ in monocytes were examined by flow-cytometry. (F) COX2 activity in efferocytosing monocytes was inhibited by using $100 \mu M$ NS-398 before adding them to CellTrace $^{\mathrm{TM}}$ Violet-labeled CD3 T cells. Proliferation of T cells was measured and analyzed by flow cytometry, $n=4$. Experimental data are expressed as means \pm standard deviation. One-way analysis of variance and the post-hoc Tukey test were used to compare the mean differences among the samples. (G) Eight steroid-resistant patients with graft-versus-host disease (GvHD) receiving mesenchymal stromal cells (MSC) were analyzed for serum PGE2 levels. The percentages of PGE2 increment [PGE2 ${ }^{\text {after infusion }}-P G E 2^{\text {before infusion }} / P G E 2^{\text {before infusion }} \times 100 \%$ ] were compared between clinical responders $(\bullet n=5)$ and non-responders ( $\left.n=4\right)$. An unpaired $t$ test was used to compare the mean differences between two groups ( $* P<0.05 ; * * P<0.01$; ns: not significant). 
immunosuppression and its master role in regulating IDO, PD-L1 and IL-10 induced by efferocytosis. According to previous studies, PGE2 may enhance the expression of IDO or IL10 through the induction of cyclic adenosine monophosphate and protein kinase A activation. ${ }^{9,11}$

Since COX2/PGE2 is the key effector of ApoMSCinduced immunosuppressive monocytes, we asked whether PGE2 levels could reflect the MSC immunological activity in patients with GvHD receiving MSC treatment. This choice presents a major advantage compared to monitoring IDO activity. Although we previously identified IDO as the ultimate effector of ApoMSC in GvHD, the current method of determining IDO activity ${ }^{12}$ remains to be optimized. Soluble factors such as PGE2 serve as a simpler and more cost-effective approach to monitoring MSC immunological effects.

Between July 2016 and August 2017, eight patients with severe steroid-resistant GvHD were treated with MSC at the University Hospital Carl Gustav Carus (TU Dresden, Germany). MSC were generated from the bone marrow of multiple third-party donors and expanded under Good Manufacturing Practice conditions in Dresden Stem Cell Laboratory. ${ }^{13}$ The treatment was made according to Regulation (European Commission) number 1394/2007. The patients' characteristics are summarized in Table 1. The diagnosis of GvHD was made according to standard criteria. ${ }^{14} \mathrm{Clinical}$ responses to MSC, defined by a reduction of at least one grade in GvHD in any organ after infusion, were assessed 1 week after the infusion. ${ }^{1,13}$ Donors and patients provided informed consent (Technische Universität Dresden, EK206082008).

The average (mean \pm standard deviation) MSC dose was $1.68 \pm 0.62 \times 10^{6} / \mathrm{kg}$, with the dose ranging from 1.02 to $2.28 \times 10^{6} / \mathrm{kg}$. Four patients achieved a partial response. One of the responders received two independent MSC infusions and, accordingly, was assessed twice. Four patients were non-responders. Serum samples were collected from patients 1 day before MSC infusion and then between 1 and 4 days (median 4 days) after the infusion and examined for PGE2 levels (Figure 2G, Online Supplementary Figure $S 3 A, B)$. In order to compare the results across patients, we calculated the change in PGE2 levels before and after MSC infusion using the formula $\left.\left[\mathrm{PGE} 2^{\text {after infusion }}-\mathrm{PGE} 2^{\text {before infusion }}\right] / \mathrm{PGE} 2^{\text {before infusion }} \times 100 \%\right]$. The percentage of PGE2 increment was significantly higher in clinical responders than in non-responders, in whom PGE2 levels remained unchanged (Figure 2G). We are aware that the number of patients assessed is small and larger prospective studies are needed to validate our findings. Furthermore, it would be interesting to assess whether the phagocytes in responders and non-responders exhibit any functional difference in efferocytosis.

Overall, this study further strengthens the role of in vivo MSC apoptosis in delivering immunosuppression. ${ }^{4,15}$ By showing that efferocytosis of ApoMSC results in PGE2-dependent immunosuppression, our study is a step forward towards our understanding of the immunomodulatory role of MSC apoptosis. We, therefore, suggest that PGE2 monitoring could estimate the immunological activity of MSC therapy in GvHD patients.

Tik Shing Cheung, Antonio Galleu,' Malte von Bonin, ${ }^{2}$ Martin Bornhäuser and Francesco Dazzi'
'School of Cancer and Pharmacological Sciences and KHP Cancer Research UK Centre, King's College London, London, United Kingdom; 'University Hospital Carl Gustav Carus, Dresden, Germany

Funding: this work was funded by the Bloodwise Specialist Programme 14019. TSC is a recipient of Hong Kong Scholarships from The King's College London Hong Kong Foundation Ltd and Chinese Student Awards from the Great Britain-China Educational Trust, AG is the recipient of the Bloodwise Clinical Training Fellowship 15029

Correspondence: FRANCESCO DAZZI.

francesco.dazzi@kcl.ac.uk

doi:10.3324/haematol.2018.214767

Information on authorship, contributions, and financial \& other disclosures was provided by the authors and is available with the online version of this article at www. haematologica.org.

\section{References}

1. Galleu A, Milojkovic D, Deplano S, et al. Mesenchymal stromal cells for acute graft-versus-host disease: response at 1 week predicts probability of survival. Br J Haematol. 2019;185(1):89-92.

2. Le Blanc K, Frassoni F, Ball L, et al. Mesenchymal stem cells for treatment of steroid-resistant, severe, acute graft-versus-host disease: a phase II study. Lancet. 2008;371(9624):1579-1586.

3. Cheung TS, Dazzi F. Mesenchymal-myeloid interaction in the regulation of immunity. Semin Immunol. 2018;35:59-68.

4. Galleu A, Riffo-Vasquez Y, Trento C, et al. Apoptosis in mesenchymal stromal cells induces in vivo recipient-mediated immunomodulation. Sci Transl Med. 2017;9(416)

5. de Witte SFH, Luk F, Sierra Parraga JM, et al. Immunomodulation by therapeutic mesenchymal stromal cells (MSC) is triggered through phagocytosis of MSC by monocytic Cells. Stem Cells. 2018; 36(4):602-615.

6. Miksa M, Komura H, Wu R, Shah KG, Wang P. A novel method to determine the engulfment of apoptotic cells by macrophages using pHrodo succinimidyl ester. J Immunol Methods. 2009;342(1-2):7177

7. Raetz CRH, Whitfield C. Lipopolysaccharide endotoxins. Annu Rev Biochem. 2002;71(1):635-700.

8. Yatim N, Cullen S, Albert ML. Dying cells actively regulate adaptive immune responses. Nat Rev Immunol. 2017;17(4):262-275.

9. Braun D, Longman RS, Albert ML. A two-step induction of indoleamine 2,3 dioxygenase (IDO) activity during dendritic-cell maturation. Blood. 2005;106(7):2375-2381

10. Prima V, Kaliberova LN, Kaliberov S, Curiel DT, Kusmartsev S. COX2/mPGES1/PGE2 pathway regulates PD-L1 expression in tumor-associated macrophages and myeloid-derived suppressor cells. Proc Natl Acad Sci U S A. 2017;114(5):1117-1122.

11. MacKenzie KF, Clark K, Naqvi S, et al. PGE2 induces macrophage IL10 production and a regulatory-like phenotype via a protein kinase A-SIK-CRTC3 pathway. J Immunol. 2013;190(2):565-577.

12. Du TT, Cui T, Oiu HM, Wang NR, Huang D, Jiang XH. Simultaneous determination of tryptophan, kynurenine, kynurenic acid and two monoamines in rat plasma by HPLC-ECD/DAD. J Pharm Biomed Anal. 2018;158:8-14.

13. Von Dalowski F, Kramer M, Wermke M, et al. Mesenchymal stromal cells for treatment of acute steroid-refractory graft versus host disease: clinical responses and long-term outcome. Stem Cells. 2016; 34(2):357-366.

14. Filipovich $\mathrm{AH}$, Weisdorf $\mathrm{D}$, Pavletic $\mathrm{S}$, et al. National Institutes of Health Consensus Development Project on Criteria for Clinical Trials in Chronic Graft-versus-Host Disease: I. Diagnosis and Staging Working Group Report. Biol Blood Marrow Transplant. 2005;11(12):945-956.

15. Chang C-L, Leu S, Sung H-C, et al. Impact of apoptotic adiposederived mesenchymal stem cells on attenuating organ damage and reducing mortality in rat sepsis syndrome induced by cecal puncture and ligation. J Transl Med. 2012;10(1):244. 